\title{
Source-Reconstruction of Event-Related Fields Reveals Hyperfunction and Hypofunction of Cortical Circuits in Antipsychotic-Naive, First-Episode Schizophrenia Patients during Mooney Face Processing
}

\author{
Davide Rivolta, ${ }^{1,2,3}$ Nazareth P. Castellanos, ${ }^{4}$ Cerisa Stawowsky, ${ }^{5}$ Saskia Helbling, ${ }^{6}$ Michael Wibral, ${ }^{5}$ Christine Grützner, ${ }^{1}$ \\ Dagmar Koethe, ${ }^{7,8,9}$ Katharina Birkner, ${ }^{1,2}$ Laura Kranaster, ${ }^{7,8}$ Frank Enning, ${ }^{8}$ Wolf Singer, ${ }^{1,2,10}$ F. Markus Leweke, ${ }^{7,8 *}$ \\ and Peter J. Uhlhaas ${ }^{1,2,11 \star}$ \\ ${ }^{1}$ Department of Neurophysiology, Max Planck Institute for Brain Research and ${ }^{2}$ Ernst Strüngmann Institute (ESI) for Neuroscience in Cooperation with \\ Max Planck Society, Frankfurt am Main 60528, Germany, ${ }^{3}$ School of Psychology, University of East London, London E15 4LZ, United Kingdom, \\ ${ }^{4}$ Laboratory of Cognitive and Computational Neuroscience, Center for Biomedical Technology, Universidad Politécnica de Madrid, Madrid 28223, Spain, \\ ${ }^{5}$ MEG Unit, Brain Imaging Centre, Johann Wolfgang Goethe University, Frankfurt am Main 60529, Germany, ${ }^{\circ}$ Institute for Medical Psychology, Johann \\ Wolfgang Goethe University, Frankfurt am Main 60054, Germany, ${ }^{7}$ Department of Psychiatry and Psychotherapy, University of Cologne, Cologne 50924, \\ Germany, ${ }^{8}$ Department of Psychiatry and Psychotherapy, Central Institute of Mental Health, Medical Faculty Mannheim, Heidelberg University, Mannheim \\ 68159, Germany, ${ }^{9}$ Department of General Psychiatry, Medical Faculty Heidelberg, Heidelberg University, Heidelberg 69115, Germany, ${ }^{10}$ Frankfurt Institute \\ for Advanced Studies, Johann Wolfgang Goethe University, Frankfurt am Main 60438, Germany, and ${ }^{11}$ Institute of Neuroscience and Psychology, \\ University of Glasgow, Glasgow G12 8QB, United Kingdom
}

Schizophrenia is characterized by dysfunctions in neural circuits that can be investigated with electrophysiological methods, such as EEG and MEG. In the present human study, we examined event-related fields (ERFs), in a sample of medication-naive, first-episode schizophrenia (FE-ScZ) patients $(n=14)$ and healthy control participants $(n=17)$ during perception of Mooney faces to investigate the integrity of neuromagnetic responses and their experience-dependent modification. ERF responses were analyzed for M100, M170, and M250 components at the sensor and source levels. In addition, we analyzed peak latency and adaptation effects due to stimulus repetition. FE-ScZ patients were characterized by significantly impaired sensory processing, as indicated by a reduced discrimination index $\left(\mathrm{A}^{\prime}\right)$. At the sensor level, M100 and M170 responses in FE-ScZ were within the normal range, whereas the M250 response was impaired. However, source localization revealed widespread elevated activity for M100 and M170 in FE-ScZ and delayed peak latencies for the M100 and M250 responses. In addition, M170 source activity in FE-ScZ was not modulated by stimulus repetitions. The present findings suggest that neural circuits in FE-ScZ may be characterized by a disturbed balance between excitation and inhibition that could lead to a failure to gate information flow and abnormal spreading of activity, which is compatible with dysfunctional glutamatergic neurotransmission.

Key words: ERFs; face processing; first-episode psychosis; M170; MEG; Mooney faces

\section{Introduction}

Event-related potentials (ERPs) and their neuromagnetic counterparts, event-related fields (ERFs), reveal the timing of neuronal events underlying sensory and cognitive processes with millisecond precision. In addition to important insights into nor-

Received Sept. 2, 2013; revised March 4, 2014; accepted March 7, 2014.

Author contributions: M.W., C.G., D.K., L.K., F.E., W.S., F.M.L., and P.J.U. designed research; C.G., D.K., L.K., and

F.E. performed research; D.R., N.P.C., C.S., S.H., M.W., and K.B. analyzed data; D.R. and P.J.U. wrote the paper.

D.R. received support from LOEWE Grant Neuronale Koordination Forschungsschwerpunkt Frankfurt (NeFF).

Peter J. Uhlhaas and Wolf Singer were supported by the Max-Planck Society.

The authors declare no competing financial interests.

Correspondence should be addressed to Dr. Peter J. Uhlhaas, Institute of Neuroscience and Psychology, University

of Glasgow, Hillead Str. 58, Glasgow G12 8QB, United Kingdom. E-mail: peter.uhlhaas@glasgow.ac.uk.

${ }^{*}$ M.F.L. and P.J.U. contributed equally to this work.

DOI:10.1523/JNEUROSCI.3752-13.2014

Copyright $\odot 2014$ the authors $\quad 0270-6474 / 14 / 345909-09 \$ 15.00 / 0$ mal brain functioning, ERPs/ERFs have been used to identify aberrant cortical processes in schizophrenia (ScZ; Luck et al., 2011). These studies have revealed impairments both in the latency and amplitude of ERP/ERF components for early, sensorydriven potentials, such as the P50 (Freedman et al., 1983) and P/M100 (Doniger et al., 2002), and later components, such as N/M170 (Herrmann et al., 2004) and P/M300 (Ford, 1999), which are involved in higher cognitive functions such as face processing and decision making (Onitsuka et al., 2006; Lee et al., 2010).

The large majority of studies investigating ERP/ERF components have been conducted in chronically medicated ScZ patients. Because antipsychotic medication has an immediate impact on brain activity (Tost et al., 2010) and may affect GABA and glutamate levels (Kegeles et al., 2012), data from medicated 
patient populations need to be complemented by patient samples that are free from the confounding influence of antipsychotics, ideally, in first-episode (FE) patients that are medication naive. Indeed, evidence on the presence of ERP/ERF abnormalities in FE-ScZ has been less consistent, suggesting potential differences in the underlying pathophysiological mechanisms during different illness stages. For example, mismatch negativity aberrations have been found to be more impaired in chronic than in FE-ScZ patients (Umbricht et al., 2006), with some studies failing to find a deficit at illness onset (Salisbury et al., 2002). Similarly, P50 and N100 responses during sensory gating have been found to be intact in FE-ScZ patients (Bachmann et al., 2010).

In the present study, we examined ERFs during perception of Mooney faces in a sample of never-medicated FE-ScZ patients. Mooney faces are two-tone images of human faces that are associated with face-sensitive ERP/ERF responses such as the N/M100 and N/M170 (George et al., 2005; Eimer et al., 2011) and a negative deflection occurring between 200 and $250 \mathrm{~ms}$ indexing the "closure" of incomplete visual information (Grützner et al., 2010; Castelhano et al., 2013). Previously, we had reported that FE-ScZ patients in the present sample are characterized by a dysregulation of beta/gamma-band activity during Mooney face perception (Sun et al., 2013).

To further investigate the neurophysiology of visual dysfunction in ScZ, we examined ERFs in combination with advanced source localization of face-sensitive MEG components (M100, $\mathrm{M} 170$, and M250) to identify the cortical regions and processing stages underlying impaired Mooney face perception in FE-ScZ patients. Previous work highlighted the possibility that abnormalities in early sensory-driven potentials, such as the P100, could drive impairments in higher cortical areas during perceptual tasks (Doniger et al., 2002; Dias et al., 2011) and that this pattern of dysfunction is consistent with abnormal dorsal stream activity and glutamatergic abnormalities caused by NMDAR deficits (Bickel and Javitt, 2009). In addition, neural responses of visual perceptual learning were investigated to test the experience-dependent modifications of neural responses, a process critically mediated by NMDARs (Kleinschmidt et al., 1987; Philpot et al., 2007).

\section{Materials and Methods}

\section{Participants}

Fourteen antipsychotic-naive ScZ patients (4 females) who were experiencing their first hospitalization were recruited from the Department of Psychiatry and Psychotherapy, University of Cologne, and the Department of Psychiatry, Psychosomatics and Psychotherapy, Goethe University Frankfurt. All FE-ScZ patients met DSM-IV criteria for paranoid-ScZ and the duration of untreated psychosis was 10.2 months (5.17 SD). Seventeen healthy controls (4 females) were recruited from the local community and screened for psychopathology with the German version of Structured Clinical Interview for DSM-IV-R (SCID; for demographic information for patients and controls, see Table 1). Premorbid verbal intelligence was assessed with the Mehrfachwahl-Wortschatz-Intelligenztest (MWT; Lehrl, 2005).

The study was performed according to the Declaration of Helsinki and approved by the ethical committees of the Goethe University Frankfurt and the University of Cologne. After complete description of the study to the participants, written informed consent was obtained. DSM-IV diagnosis of ScZ was established with the SCID by thorough chart review and in consultation with the treating psychiatrists. Patients and controls were excluded if they had any neurological or ophthalmologic disorders that might have affected performance or if they met criteria for alcohol or substance dependence within the last month. Current psychopathology was assessed with the Positive and Negative Syndrome Scale (PANSS; Kay et al., 1986) and symptoms were grouped into five factors according to the model of Lindenmayer et al. (1995), including the factors "positive,"
Table 1. Biographical information, MWT, performance on face/no-face stimuli, and $\mathrm{A}^{\prime}$ of healthy control participants and FE-SCZ patients and PANSS scores for FE-SCZ patients

\begin{tabular}{|c|c|c|c|c|}
\hline & \multicolumn{2}{|c|}{ Controls $(n=17)$} & \multicolumn{2}{|c|}{ FE-ScZ $(n=14)$} \\
\hline & Mean & SD & Mean & SD \\
\hline Age (years) & 22.71 & 2.44 & 25.64 & 5.33 \\
\hline Education (years) & 15.53 & 4.89 & 13.43 & 5.03 \\
\hline Handedness & 52.08 & 41.28 & 66.61 & 27.36 \\
\hline MWT & 27.18 & 10.54 & 27.36 & 8.76 \\
\hline Face (\%) & 83.13 & 6.54 & 82.87 & 10.45 \\
\hline No-face (\%) & 84.25 & 13.01 & 72.87 & 12.52 \\
\hline Face (ms) & 612 & 116 & 702 & 217 \\
\hline No-face (ms) & 766 & 136 & 913 & 255 \\
\hline$A^{\prime}$ & 0.90 & 0.01 & 0.86 & 0.01 \\
\hline \multicolumn{5}{|l|}{ PANSS } \\
\hline Negative & - & - & 18.00 & 8.01 \\
\hline Excitement & - & - & 8.79 & 4.82 \\
\hline Cognitive & - & - & 12.64 & 6.57 \\
\hline Positive & - & - & 12.86 & 5.20 \\
\hline Depression & - & - & 15.29 & 5.88 \\
\hline
\end{tabular}

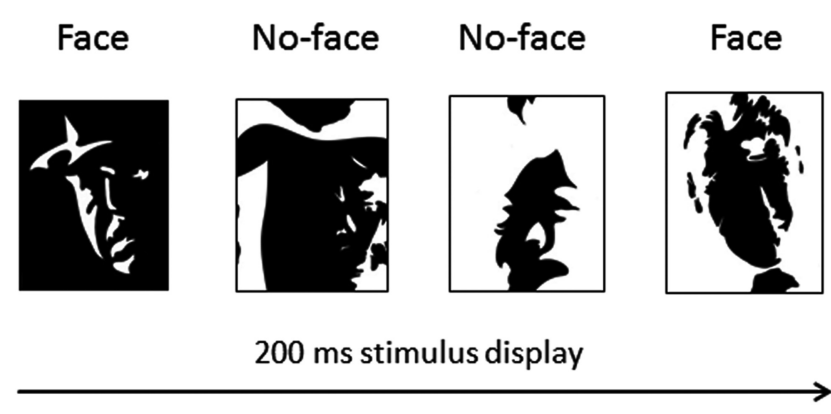

3500-4500 ms inter-stimulus interval

Figure 1. Mooney stimuli: example trial sequence. A fixation cross, not represented in the figure, was shown between each trial.

"negative," "depression," “excitement," and "cognitive." Patients with first episode and healthy controls were of similar age.

\section{Stimuli and task}

Mooney and Ferguson (1951) developed a visual closure task consisting of degraded pictures of human faces in which all shades of gray are removed. Perception of Mooney faces involves the grouping of the fragmentary parts into coherent images based on the Gestalt principle of closure. We used a set of 160 different stimuli consisting of the 40 original Mooney stimuli presented in the upright orientation, mirrored at the vertical axis, and in corresponding versions mirrored at the horizontal axis (Fig. 1). The inverted stimuli were scrambled by moving single, contiguous white or black foreground patches across the black or white background areas, respectively. Participants were presented with a random sequence of upright and inverted-scrambled stimuli that were shown for $200 \mathrm{~ms}$. The interstimulus interval ranged between 3500 and $4500 \mathrm{~ms}$. Participants indicated via button press whether a face or a no-face was presented. The hand assignment (left/right hand; face/noface response) was counterbalanced across subjects.

All participants completed four experimental runs, each of which was composed of 60 upright and 30 inverted-scrambled stimuli. The stimuli were displayed in the center of a translucent screen at a viewing distance of $53 \mathrm{~cm}$ and subtended 19 degrees of visual angle. An LCD projector located outside of the magnetically shielded room of the MEG was used to project the stimuli onto the screen via two front-silvered mirrors. Stimulus presentation was controlled using the Presentation software package (Neurobehavioral Systems).

\section{MEG data acquisition}

MEG data were acquired using a 275-sensor whole-head system (Omega 2005; VSM MedTech) with a sampling rate of $600 \mathrm{~Hz}$ in a synthetic 
Controls

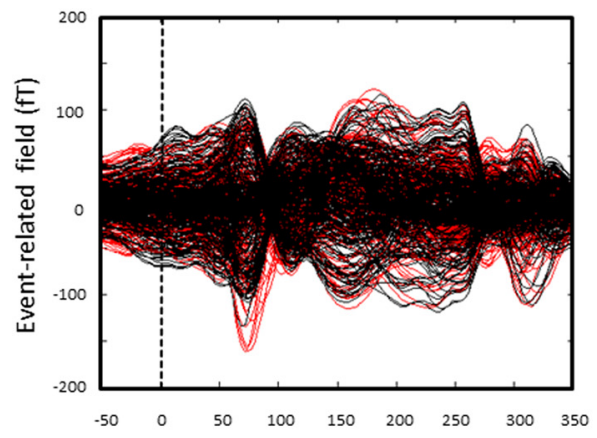

FE-ScZ

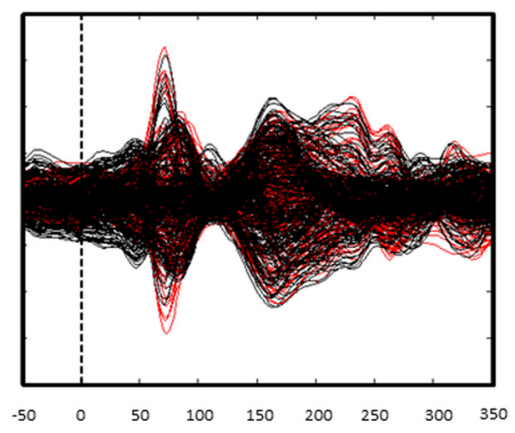

Time (ms)

Figure 2. Corresponding ERF traces for all sensors and all trials. Black, Face condition; red, no-face condition.

only trials with correct responses were considered for data analysis. Trials containing eye blinks or artifact due to muscle activity or sensors (SQUIDs) jumps were discarded using automatic artifact rejection routines. To control for the higher number of trials in the face condition versus the no-face condition, we randomly excluded face trials to obtain the same number of trials in the two conditions for each participant. Overall, controls had a mean of 79 trials (SEM $=5.5)$ for each condition, whereas FE-ScZ had 58 trials $($ SEM $=3.8)$. Statistics at the sensor and at source level were calculated within three time windows: M100 (70-100 $\mathrm{ms}), \mathrm{M} 170$ (140-190 ms), and M250 (250-300 ms; Figs. 2, Fig. 3 ) and baseline corrected (baseline window: from -500 until $-100 \mathrm{~ms}$ prestimulus onset).

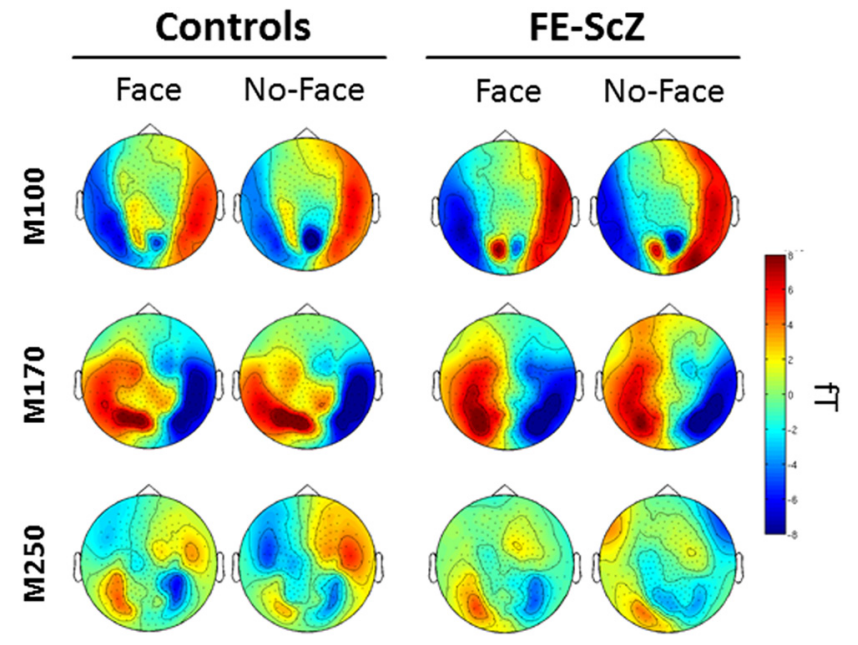

Figure 3. Sensor-level analysis. Shown are ERF topographical distributions for the M100, M170, and M250 for both controls and FE-SCZ (in femto-teslas, fT).

third-order axial gradiometer configuration. Data were offline band-pass filtered between 1 and $40 \mathrm{~Hz}$ and participants' head movements were monitored before and after each run using coils placed in the nasion and $1 \mathrm{~cm}$ anterior to the tragus of the left and right hear. Runs with movement larger than $5 \mathrm{~mm}$ were excluded from further analysis.

\section{Anatomical (MRI) data acquisition}

A high-resolution anatomical MRI scan was acquired for each participant using a 3D magnetization-prepared rapid-acquisition gradient echo sequence ( 160 slices; voxel size: $1 \times 1 \times 1 \mathrm{~mm}$; FOV: $256 \mathrm{~mm}$; TR: 2300 $\mathrm{ms}$; TE: $3.93 \mathrm{~ms}$ ). During the structural scan, vitamin E pills were applied to the nasion and $1 \mathrm{~cm}$ anterior to the tragus of the right and left ear to allow for coregistration of the MEG and MRI data. Scanning was performed with a 3 tesla Siemens Trio scanner.

\section{Behavioral data}

Reaction times (RTs) and detection rates were analyzed using a $2 \times 2$ ANOVA with "group" (controls vs FE-ScZ) as the between-subject factor and "condition" (face vs no-face) as the within-subject factor. In addition, we examined changes in behavioral parameters for face responses during the first versus the second half of trials to test for changes in perceptual learning. Statistically significant interactions were followed by post hoc $t$ tests. We also calculated the discrimination index A' (Grier, 1971) and compared it across groups using a $t$ test.

\section{$M E G$ data processing and analysis}

The preprocessing routines and calculation of ERFs was performed with Fieldtrip software (http://fieldtrip.fcdonders.nl/). Trials were defined through a $-1000 \mathrm{~ms}$ prestimulus and $1000 \mathrm{~ms}$ poststimulus interval and
Sensor-level statistics. A nonparametric mixed-design two-way ANOVA based on a permutation approach (Anderson and Ter Braak, 2003; Suckling and Bullmore, 2004) with one between-subject factor, "group" (controls vs FE-ScZ), and one within-subject factor, "condition" (face vs no-face), was used for the statistical analysis at the sensor level. The analysis was performed considering all MEG sensors. Sensors were selected when the $F$-value surpassed an $F$-value corresponding to an $\alpha$ level of 0.05 and assigned to clusters based on their spatial adjacency defined by the template implemented in Fieldtrip. Cluster-level statistics were calculated by taking the sum of the $F$-values within each cluster. These calculations were performed for each main effect and the interaction individually.

The observed cluster-level statistics were than tested against the distribution of the maximum cluster-level statistics obtained from Monte Carlo simulations with 1000 permutations for each effect. For each permutation, group and condition assignments were shuffled and the estimation of $F$-values and the clustering procedure were repeated on the resampled data. The resulting maximum cluster values were used to construct the maximum cluster-level distribution under the null hypothesis. Clusters were considered to be significant at an $\alpha$ level of 0.05 if the initially observed cluster value was greater than the 95 th percentile of the maximum cluster-level statistic distribution. Post hoc comparisons on channels showing statistically significant interactions were computed with nonparametric $t$ tests based on a permutation approach (1000 permutations).

Source-level statistics. The statistical analysis at the source level was computed with Statistical Parametrical Mapping (SPM8; http://www.fil. ion.ucl.ac.uk/spm/), adopting a Bayesian inversion of hierarchical Gaussian process models (Litvak et al., 2011). For each participant, a head mesh with 8196 vertices was obtained by computing the nonlinear transformation from the individual MRI to the template (MNI) space. In a second step, we coregistered the sensor positions to the individual MRI using the nasion and the preauricular points as fiducials and calculated the forward solution by computing the lead field for each dipole (vertex) on the cortical mesh with a "single shell" model. Finally, the inverse solution was calculated using the multiple sparse priors algorithm. For all components of interest (M100, M170, and M250), we calculated the condition $\times$ group interaction and the main effect of condition (face vs no-face) of a full-factorial $2 \times 2$ ANOVA model (two tails, $\alpha: 0.05$ ). We further performed post hoc contrasts ( $t$ tests, two tails, $\alpha$ Bonferroni corrected to 0.008 ) to test the direction of the statistically significant effects of the ANOVA.

\section{Peak latency analysis}

For each ERF-component, we extracted latency values over the anatomical regions showing the strongest source group $\times$ condition interaction (ANOVA; Tables 2, 3). These were defined based on the size of the $p$-value. When two or more regions had the same $p$-value, the region with the biggest cluster size was selected. A $2 \times 2$ ANOVA with one betweensubject factor, "group" (controls vs FE-ScZ), and one within-subject fac- 
Table 2. Anatomical regions showing statistically significant post-hoc $(t)$ comparisons for the M100, M170, and M250

\begin{tabular}{|c|c|c|c|c|c|c|}
\hline Name & Side & $x$ & $y$ & $z$ & $p$-value & $\mathrm{kE}$ \\
\hline \multicolumn{7}{|l|}{ M100 } \\
\hline \multicolumn{7}{|c|}{$\begin{array}{c}\text { No-face FE-ScZ }>\text { no-face } \\
\text { controls }(t)\end{array}$} \\
\hline Angular & R & 44 & -52 & 30 & $<0.001$ & 54 \\
\hline Frontal inf orb & L & -36 & 30 & -12 & $<0.001$ & 138 \\
\hline Frontal inf orb & $\mathrm{R}$ & 44 & 28 & -14 & $<0.001$ & 102 \\
\hline Postcentral & $\mathrm{R}$ & 24 & -40 & 54 & $<0.001$ & 129 \\
\hline Precentral & $\mathrm{R}$ & 24 & -32 & 68 & $<0.001$ & 52 \\
\hline Supramarginal & L & -52 & -50 & 24 & $<0.001$ & 102 \\
\hline Supramarginal & $\mathrm{R}$ & 34 & -36 & 40 & $<0.001$ & 86 \\
\hline Temporal Inf & $\mathrm{R}$ & 38 & -2 & -46 & $<0.001$ & 311 \\
\hline \multicolumn{7}{|c|}{$\begin{array}{l}\text { No-face controls }>\text { no-face } \\
\quad \text { FE-ScZ }(t)\end{array}$} \\
\hline Temporal pole mid & L & -28 & 12 & -36 & $<0.001$ & 247 \\
\hline \multicolumn{7}{|l|}{ No-face $>$ face $(t)$} \\
\hline Parietal sup & $\mathrm{R}$ & 20 & -70 & 52 & $<0.001$ & 143 \\
\hline Temporal inf & $\mathrm{R}$ & 38 & -2 & -46 & $<0.001$ & 265 \\
\hline Temporal mid & L & -50 & -32 & -6 & 0.002 & 4 \\
\hline Temporal pole mid & L & -28 & 12 & -36 & $<0.001$ & 191 \\
\hline \multicolumn{7}{|l|}{ M170 } \\
\hline \multicolumn{7}{|c|}{$\begin{array}{c}\text { No-face FE-ScZ }>\text { no-face } \\
\text { controls }(t)\end{array}$} \\
\hline Cingulum mid & L & -8 & 14 & 38 & $<0.001$ & 229 \\
\hline Cingulum mid & $\mathrm{R}$ & 10 & 18 & 38 & $<0.001$ & 274 \\
\hline Frontal inf orb & L & -44 & 28 & -14 & $<0.001$ & 44 \\
\hline Frontal sup orb & L & -24 & 60 & -4 & $<0.001$ & 203 \\
\hline Postcentral & $\mathrm{R}$ & 36 & -36 & 58 & 0.003 & 27 \\
\hline Precentral & R & 24 & -32 & 68 & $<0.001$ & 24 \\
\hline Supramarginal & L & -56 & -50 & 30 & 0.007 & 40 \\
\hline \multicolumn{7}{|c|}{$\begin{array}{l}\text { No-face controls }>\text { no-face } \\
\quad \text { FE-ScZ }(t)\end{array}$} \\
\hline Frontal inf tri & R & 46 & 38 & 2 & $<0.001$ & 218 \\
\hline Occipital inf & L & -20 & -98 & -6 & $<0.001$ & 179 \\
\hline \multicolumn{7}{|l|}{ No-face $>$ face $(t)$} \\
\hline Cingulum mid & L & -8 & 14 & 38 & $<0.001$ & 194 \\
\hline Cingulum mid & $\mathrm{R}$ & 10 & 18 & 38 & $<0.001$ & 221 \\
\hline Frontal sup orb & L & -24 & 60 & -4 & $<0.001$ & 159 \\
\hline Frontal inf tri & $R$ & 48 & 38 & 2 & 0.001 & 113 \\
\hline Occipital inf & L & -20 & -96 & -6 & 0.004 & 65 \\
\hline \multicolumn{7}{|l|}{ M250 } \\
\hline \multicolumn{7}{|c|}{$\begin{array}{c}\text { No-face FE-ScZ }>\text { no-face } \\
\text { controls }(t)\end{array}$} \\
\hline Frontal inf oper & L & -54 & 14 & 12 & $<0.001$ & 159 \\
\hline Frontal sup & L & -18 & 2 & 54 & $<0.001$ & 68 \\
\hline Precuneus & $\mathrm{R}$ & 8 & -60 & 60 & $<0.001$ & 191 \\
\hline Precuneus & L & -8 & -62 & 60 & $<0.001$ & 203 \\
\hline \multicolumn{7}{|c|}{$\begin{array}{l}\text { No-face controls }>\text { no-face } \\
\quad \text { FE-ScZ }(t)\end{array}$} \\
\hline Postcentral & $\mathrm{R}$ & 22 & -38 & 58 & $<0.001$ & 173 \\
\hline \multicolumn{7}{|l|}{ No-face $>$ face $(t)$} \\
\hline Frontal inf oper & L & -54 & 14 & 12 & $<0.001$ & 110 \\
\hline Postcentral & $\mathrm{R}$ & 24 & -38 & 56 & $<0.001$ & 183 \\
\hline Precuneus & L & -8 & -62 & 60 & $<0.001$ & 169 \\
\hline Precuneus & $\mathrm{R}$ & 8 & -60 & 62 & $<0.001$ & 148 \\
\hline
\end{tabular}

Side (right, $\mathrm{R}$; left, $\mathrm{L})$, coordinates $(x, y$, and $z$ ) in MNI space, $p$ values, and cluster size (kE) are reported. Abbreviations: inf, inferior; sup, superior; mid, middle; orb, orbital; tri, pars triangularis; oper, operculum.

tor, "condition" (face vs no-face), was used for the latencies statistical analysis.

\section{Perceptual learning}

To examine the effects of stimulus repetition on ERF responses, we performed a within-group median-split analysis of amplitude values in the face condition. In particular, for each subject, we divided trials in first and second half according to their presentation order and compared
Table 3. Anatomical regions showing the strongest group $\times$ category interaction (ANOVA)

\begin{tabular}{llllllll}
\hline Name & Side & \multicolumn{1}{l}{$x$} & $y$ & $z$ & $p$-value & kE & MEG \\
\hline Middle orbitofrontal cortex & $\mathrm{L}$ & -18 & 50 & -13 & $<0.001$ & 548 & M100 \\
Parahippocampal gyrus & $\mathrm{L}$ & -22 & -20 & -24 & $<0.001$ & 765 & M170 \\
Inferior frontal gyrus & $\mathrm{R}$ & 50 & 38 & 2 & $<0.001$ & 204 & M250
\end{tabular}

Amplitude and peak latencies values of these regions were extracted for the calculation of correlation with PANSS scores. Side (right, $\mathrm{R}$; left, L), MNI coordinates $(x, y$, and $z), p$ values, cluster size ( $\mathrm{kE})$, and MEG component showing the effect are reported.

Table 4. Anatomical regions selected for the preparations of anatomical masks adopted in the calculation of the stimulus repetition effect because they showed a main effect of condition and/or a group $\times$ condition interaction

\begin{tabular}{|c|c|c|c|c|c|}
\hline \multicolumn{2}{|l|}{ M100 } & \multicolumn{2}{|l|}{ M170 } & \multicolumn{2}{|l|}{ M250 } \\
\hline Name & Side & Name & Side & Name & Side \\
\hline Angular & $\mathrm{R}$ & Angular & $\mathrm{R}$ & Angular & L \\
\hline Calcarine & L & Calcarine & $\mathrm{R}$ & Angular & $\mathrm{R}$ \\
\hline Calcarine & $\mathrm{R}$ & Cingulate mid & L & Calcarine & L \\
\hline Frontal inf orb & L & Cingulate mid & $\mathrm{R}$ & Calcarine & $\mathrm{R}$ \\
\hline Frontal inf tri & $\mathrm{R}$ & Cuneus & L & Cingulate ant & $\mathrm{R}$ \\
\hline Frontal mid orb & L & Cuneus & $\mathrm{R}$ & Frontal inf oper & L \\
\hline Fusiform & L & Frontal inf orb & L & Frontal inf tri & $\mathrm{R}$ \\
\hline Fusiform & $\mathrm{R}$ & Frontal inf orb & $\mathrm{R}$ & Frontal mid & L \\
\hline Lingual & R & Frontal inf tri & $\mathrm{R}$ & Frontal mid & $\mathrm{R}$ \\
\hline Parietal inf & R & Frontal mid & L & Postcentral & $\mathrm{R}$ \\
\hline Parietal sup & $R$ & Frontal sup orb & L & Precuneus & L \\
\hline Postcentral & L & Fusiform & $\mathrm{R}$ & Precuneus & $\mathrm{R}$ \\
\hline Postcentral & $R$ & Lingual & L & & \\
\hline Precentral & $R$ & Occipital inf & L & & \\
\hline Precuneus & L & Occipital mid & L & & \\
\hline Rolandic oper & $R$ & Parahippocampal & L & & \\
\hline Supp motor area & $R$ & Postcentral & L & & \\
\hline Supramarginal & L & Postcentral & $\mathrm{R}$ & & \\
\hline Supramarginal & $R$ & Precentral & $\mathrm{R}$ & & \\
\hline Temporal inf & L & Supramarginal & $\mathrm{R}$ & & \\
\hline Temporal inf & $R$ & Temporal sup & L & & \\
\hline Temporal mid & L & & & & \\
\hline Temporal mid & L & & & & \\
\hline
\end{tabular}

Abbreviations: inf, inferior; sup, superior; mid, middle; orb, orbital; tri, pars triangularis; oper, operculum; ant, anterior.

them at the source level using multiple $t$ tests with SPM. We restricted the analysis to those anatomical regions that previously showed significant main effects of condition and interactions at the source level (for a list of the masks adopted, see Table 4). The ROI selection was performed using the WFU-PickAtlas (http://fmri.wfubmc.edu/software/PickAtlas). Because of the multiple $t$ tests involved, the $\alpha$ level was set at 0.0083 .

Correlations of MEG activity, behavior variables, and PANSS ratings

For each ERF component, we extracted amplitude and latency values over the anatomical regions showing the strongest source group $\times$ condition interaction (Table 3). We then calculated Pearson correlation coefficients between amplitude values and Mooney face accuracy and RT data $(\alpha=0.025)$. We also calculated Pearson correlation coefficients between amplitude values and the five PANSS subscales (negative, excitement, cognitive, positive, depression; $\alpha=0.01$ ).

\section{Results}

\section{Behavioral results}

A main effect of group showed that controls were overall more accurate than FE-ScZ patients $\left(F_{(1,29)}=6.76, p=0.015\right)$. However, there was no effect of condition $\left(F_{(1,29)}=1.90, p=0.179\right)$ nor a group by condition interaction $\left(F_{(1,29)}=2.97, p=0.095\right)$. RTs showed a main effect of condition $\left(F_{(1,29)}=50.12, p<\right.$ 0.001 ), with face responses being faster than RTs for no-faces. There was a trend for slowed responses in the FE-ScZ group 


\section{Face vs. No-face}
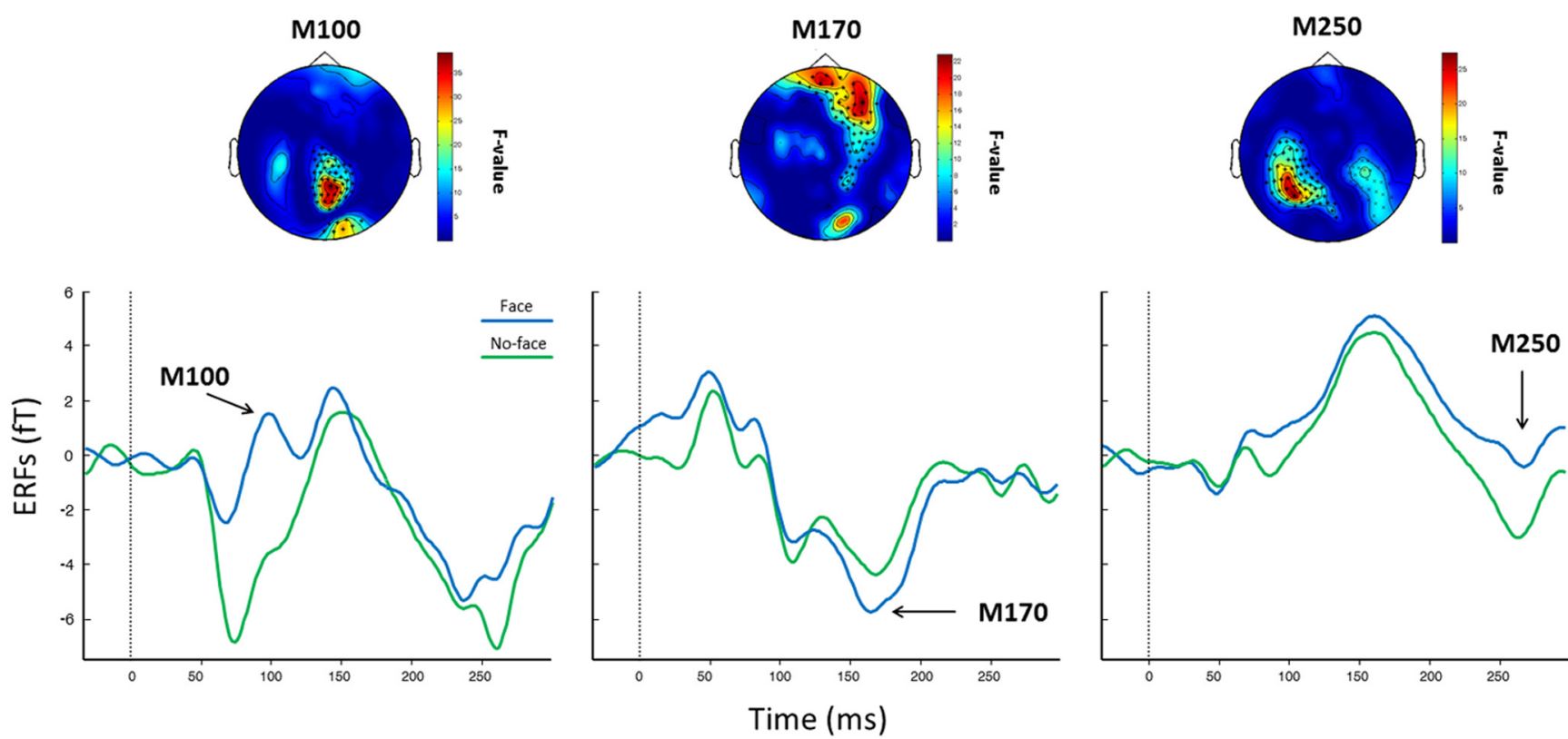

Figure 4. Sensor-level statistics. Shown is the main effect of condition (face vs no-face) for the M100 (left), M170 (middle), and M250 (right). Top, Topoplot indicating the $F$-map distribution. Statistically significant channels are highlighted. ${ }^{*} p<0.01 ; x=p<0.05$. Bottom, Face and no-face ERFs averages over sensors showing a statistically significant $F$-value.

\section{M250: Interaction}
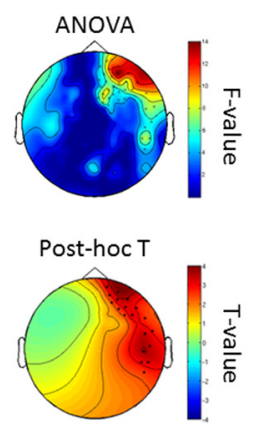

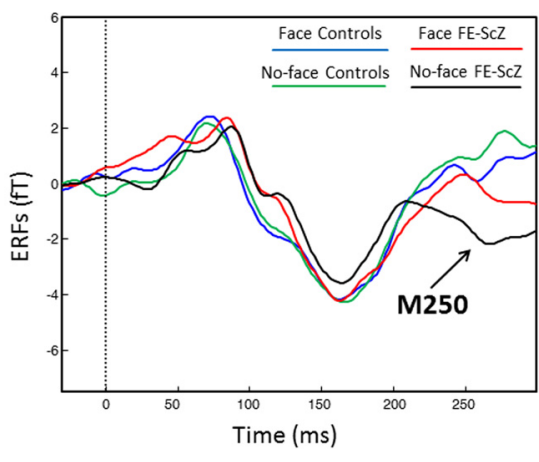

Figure 5. Sensor-level statistics: Shown is the group $\times$ condition interaction for the M250. Left, $F$-value (top) and $T$-value (bottom) distribution highlighting, respectively, the statistically significant channels for the ANOVA and for the post hoc analysis. ${ }^{*} p<0.01 ; x=p<0.05$. Right, ERF averages for the face and no-face conditions in controls and FE-SCZ over sensors showing statistically significant effects.

$\left(F_{(1,29)}=3.73, p=0.063\right)$, but no group by condition interaction $\left(F_{(1,29)}=1.22, p=0.278\right)$. The discrimination index $\mathrm{A}^{\prime}$ (Grier, $1971)$ indicated that controls had a better discrimination performance compared with FE-ScZ patients $\left(t_{(29)}=2.41, p=0.023\right.$; Table 1).

The $2 \times 2$ ANOVA to examine differences in perceptual learning showed a trend toward a statistically significant group $\times$ presentation interaction for RTs $\left(F_{(1,29)}=3.88, p=0.059\right)$, indicating that RTs did not improve in FE-ScZ patients through stimulus repititions. No main effect was statistically significant $(p>$ $0.05)$. The analysis of accuracy did not reveal main effects nor interaction $(p>0.05)$.

\section{MEG results: sensor data}

A main effect of condition for the amplitude of the M100 component was found, with face responses showing higher positive amplitude in occipitoparietal sensors (Fig. 4). Similarly, there was a main effect of condition for the M170 and face responses were characterized by higher negative amplitude in frontocentral sensors compared with no-face responses (Fig. 4). There were no main effects of group or group $\times$ condition interactions for either the M100 or the M170 amplitudes. In contrast, a main effect of condition for the M250 indicated that the no-face condition elicited higher activity in temporoparietal sensors bilaterally (Fig. $4)$. There also was a condition $\times$ group interaction over frontotemporal sensors, indicating that controls had increased M250 responses for no-faces relative to the FE-ScZ group (Fig. 5).

\section{MEG results: source data}

For condition effects (face vs no-face responses), there were statistically significant main effects of condition for any component. Post hoc comparisons showed increased M100 responses for face versus no-face responses in the left middle orbitofrontal lobe, right inferior frontal gyrus (pars triangularis), left precuneus, and right and left fusiform gyrus. M170 responses were higher in the face condition in a network including the fusiform gyrus (bilateral), the left parahippocampal gyrus, the right cuneus, the left medial occipital gyrus, and the postcentral gyrus (bilateral). Finally, M250 face activity was elevated in the right inferior frontal gyrus (pars triangularis) compared with the no-face condition (Fig. 6).

For the condition $\times$ group interaction (controls vs FE-ScZ), source analysis revealed statistically significant condition $X$ group interactions for M100, M170, and M250. Post hoc comparisons showed that FE-ScZ generated stronger M100 responses than controls to stimuli in the face condition within the left middle orbitofrontal lobe, bilateral right inferior frontal gyrus (pars triangularis), left precuneus, right fusiform gyrus, and left calcarine area (Fig. 7). Similarly, activity in the no-face condition was elevated in FE-ScZ patients in the orbitofrontal cortex bilaterally, supramarginal gyrus (bilateral), inferior temporal gyrus, and right angular gyrus (Table 2). The only region where controls 


\section{Face $>$ No-face}

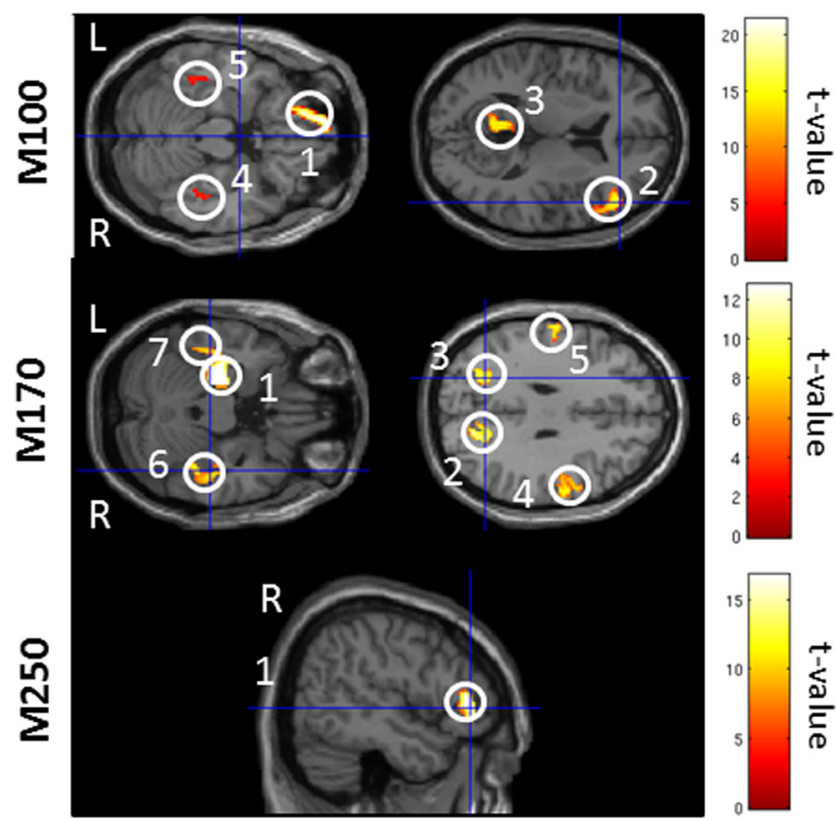

Figure 6. Source reconstructions: $t$-contrasts for face versus no-face. For M100: (1) left middle orbitofrontal lobe $(-18,50,-16)$; (2) right inferior frontal gyrus (pars triangularis; 48,38 , 2); (3) left precuneus $(-8,-54,14)$; (4) right fusiform gyrus $(44,-34,-20)$; and (5) left fusiform gyrus $(-44,-38,-20)$. For M170: (1) left parahippocampal gyrus $(-22,-24$, $-22)$; (2) right cuneus $(16,-70,30)$; (3) left middle occipital gyrus $(-24,-62,32)$; (4) right postcentral gyrus $(-62,-12,26)$; (5) left postcentral gyrus $(64,-10,18)$; (6) right fusiform gyrus (42, -38, -24); and (7) left fusiform gyrus ( $-44,-40,22)$. For M250: (1) right inferior frontal gyrus (pars triangularis; 50, 60, 4). L, Left hemisphere; $R$, right hemisphere.

showed increased activity relative to the FE-ScZ group was within the left middle temporal pole during the no-face condition (Table 2).

M170 amplitudes to face responses in FE-ScZ patients generated stronger activity than in controls within the fusiform gyrus (bilateral), left parahippocampal gyrus, lingual gyrus, and middle frontal gyrus. Conversely, controls showed higher face activity in the left medial occipital gyrus and the right cuneus (Fig. 7). In the no-face condition, FE-ScZ patients were characterized by elevated activity within the left frontal superior and inferior orbital cortex, cingulate cortex (bilateral), left supramarginal gyrus, and right precentral and postcentral gyri. In contrast, controls showed higher no-face activity within the left inferior occipital gyrus and the right inferior frontal lobe (pars triangularis) relative to the FE-ScZ group (Table 2).

The analysis of the M250 indicated higher face-related activity in controls in the medial frontal gyrus (bilateral) and the right inferior frontal gyrus (pars triangularis; Fig. 7), whereas FE-ScZ were characterized by a circumscribed increase relative to controls within the precuneus (bilaterally), left inferior frontal lobe (pars opercularis), and the medial part of the left superior frontal lobe during the no-face condition. In addition, controls showed higher no-face activity than FE-ScZ within the right postcentral gyrus (Table 2).

\section{ERF latencies}

The analysis of the M100 revealed a main effect of group, with controls showing an earlier M100 peak than FE-ScZ patients (controls: mean $=80 \mathrm{~ms}, \mathrm{SEM}=2.1$; FE-ScZ: mean $=96 \mathrm{~ms}$, $\mathrm{SEM}=2.3 ; \mathrm{F}(1,29)=25.74, p<0.001)$. The group $\times$ condition interaction indicated that the difference between controls and FE-ScZ was higher in the no-face (mean $=21 \mathrm{~ms}, \mathrm{SEM}=3.2$ ) than the face condition $\left(\right.$ mean $=11 \mathrm{~ms}, \mathrm{SEM}=4.5 ; F_{(1,29)}=4.53, p=$ 0.042 ). However, there was no main effect or interaction for the M170. In contrast, the analysis of the M250 showed a main effect of condition (face: mean $=271 \mathrm{~ms}$, SEM $=3.2$; no-face: mean $=280$ $\left.\mathrm{ms}, \mathrm{SEM}=3.5 ; F_{(1,29)}=5.91, p=0.021\right)$ and a group $\times$ condition interaction $\left(F_{(1,29)}=14.00, p<0.001\right)$. Post hoc analysis showed that controls $($ mean $=261 \mathrm{~ms}, \mathrm{SEM}=4.3)$ had an earlier peak latency in the face condition than FE-ScZ (mean $=280 \mathrm{~ms}, \mathrm{SEM}=4.8 ; p=$ $0.007)$, and that the face component (mean $=261 \mathrm{~ms}, \mathrm{SEM}=4.3$ ) peaked faster than the no-face component $($ mean $=285 \mathrm{~ms}, \mathrm{SEM}=$ 4.6) in controls only $(p<0.001)$.

\section{Perceptual learning}

M100 and M250 components showed no differences between the first and the second half of trials in both groups. However, the M170 was characterized by significantly reduced activity in later trials in controls within the medial cingulate cortex (bilateral), the right fusiform gyrus, and the left parahippocampal gyrus (Fig. 8). In contrast to controls, no change in the M170 amplitude was observed in FE-ScZ during stimulus repetition.

\section{Correlation between MEG activity and behavioral performance}

Results showed a negative correlation between no-face M100 activity and ratings on the excitement $\left(r_{(14)}=-0.66, p=0.010\right)$ and cognitive dimensions $\left(r_{(14)}=-0.679, p=0.008\right)$. No additional correlation reached statistical significance.

\section{Discussion}

Here, we demonstrate that source-reconstructed ERFs in medication-naive FE-ScZ patients reveal a complex pattern of hyperfunction and hypofunction of early visual regions and higher cortical areas, which suggests the possibility of a disturbed balance in excitation and inhibition (E/I balance). This contrasts with the prominent evidence of reduced amplitudes of ERP/ERF responses in ScZ, especially in chronic ScZ patients (Onitsuka et al., 2006; Lee et al., 2010). In addition, given the aberrant perceptual learning during repetition suppression, a process that implicates NMDARs (Schmidt et al., 2013b), our results are potentially compatible with abnormal glutamatergic neurotransmission during the early stages of psychosis.

\section{Mooney faces and ERFs: sensor- and source-level analysis} Consistent with previous electrophysiological studies (Liu et al., 2002; Schweinberger et al., 2002; Rivolta et al., 2012c), facesensitive MEG components (M100, M170, and M250) showed prominent activity over posterior-lateral sensors (Fig. 3). In addition to the sensor-level analysis, we used an advanced sourcelocalization approach (Litvak et al., 2011) for the detection of ERF components.

M100 is the earliest face component and is crucial for face detection (Liu et al., 2002) and familiarity processing (Rivolta et al., 2012c). M100 activity to face stimuli was elevated in the frontal (i.e., left orbitofrontal cortex and right inferior frontal cortex), temporal (i.e., bilateral fusiform gyri), and parietal (i.e., left precuneus) regions. The activation of frontal circuits with a latency $\sim 100$ ms is consistent with previous intracranial recordings (Barbeau et al., 2008) and MEG studies (Bar et al., 2006), suggesting an initial matching of feedforward-mediated sensory processing with memory templates in frontal regions (Liu et al., 2010), which 

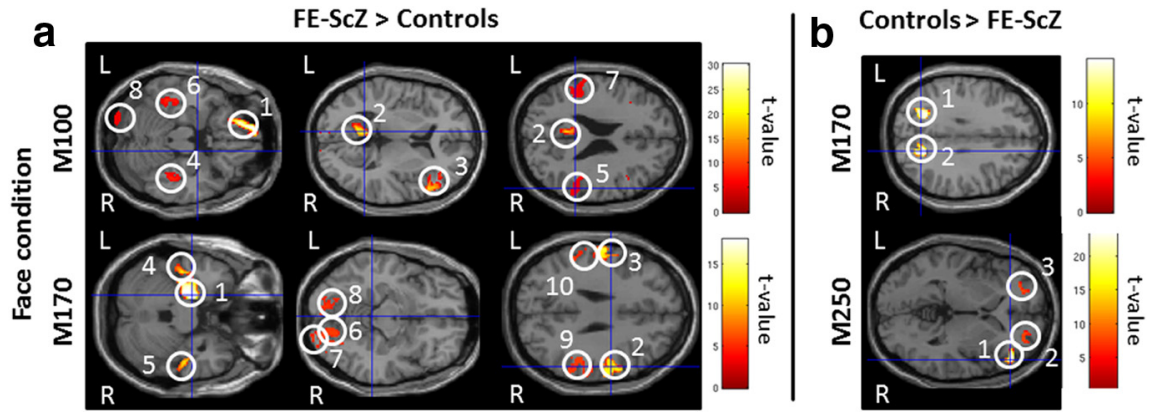

Figure 7. Source reconstructions of the face condition showing $t$-maps of FE-ScZ $>$ controls $(\boldsymbol{a})$ and controls $>\mathrm{FE}-\mathrm{ScZ}(\boldsymbol{b}) . \boldsymbol{a}$, For M100: (1) left mid-orbitofrontal gyrus $(-18,50,-16)$; (2) left precuneus $(-8,-52,12)$; (3) right inferior frontal gyrus (pars triangularis; 54, 24, 4); (4) right fusiform gyrus $(44,-34,-20)$; (5) right superior temporal lobe $(56,-42,14)$; (6) left inferior temporal gyrus $(-42,-34,-18)$; (7) left rolandic operculum $(-46,-28,16)$; and (8) left calcarine cortex $(-4,-92,-12)$. For M170: (1) left parahippocampal gyrus $(-22,-24,-22)$; (2) right postcentral gyrus $(64,-10,18)$; (3) left postcentral $(-62$, $-12,26)$; (4) left fusiform gyrus $(-44,-40,22)$; (5) right fusiform gyrus $(42,-38,-24)$; (6) right lingual gyrus $(10,-82,-8)$; (7) right inferior occipital gyrus $(38,-82,-16)$; (8) left lingual gyrus $(-12,-94,-18)$; (9) right superior temporal gyrus (62, $-42,22)$; and (10) left superior temporal gyrus ( $-50,-36,12)$. $\boldsymbol{b}$, For M170: (1) left middle occipital gyrus $(-24,-62,32)$; (2) right cuneus $(18,-68,28)$. For M250: (1) right inferior frontal gyrus (pars triangularis; $50,38,2)$; (2) right middle frontal gyrus (26, $48,2)$; and (3) left middle frontal gyrus ( $-26,46,2)$. L, Left hemisphere; $R$, right hemisphere.

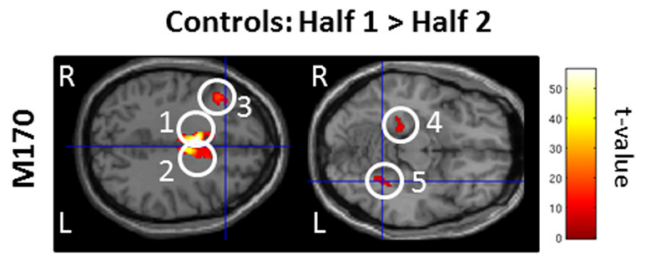

Figure 8. Source reconstruction for the M170. Shown are $T$-contrasts between the first (Half 1) and the second (Half 2) half of trials showing activity in: (1) left middle cingulate cortex ( -4 , $0,34)$; (2) right middle cingulate cortex $(4,-8,32)$; (3) left middle frontal gyrus $(-36,26$, $-42)$; (4) left parahippocampal gyrus ( $-22,-8,-32)$; and (5) right fusiform gyrus $(34,0$, -38). L, Left hemisphere; $R$, right hemisphere.

could guide further processing in posterior brain areas (Lafontaine et al., 2013).

The M/N170 has been previously shown to mediate the processing of face features, holistic processing, and memory for faces (Harris and Aguirre, 2008; Harris and Nakayama, 2008; Caharel et al., 2011; Rivolta et al., 2012b). Consistent with these functions, the sources of the M170 originated in the left middle occipital gyrus, fusiform gyri, and left parahippocampal gyrus (GornoTempini et al., 1998; Leveroni et al., 2000). Previous evidence suggested that activity in the latency range of the M250 mediates perceptual closure (Doniger et al., 2002), which is likely relevant for the perception of Mooney faces (Grützner et al., 2010). In our study, the M250 was localized to the right inferior frontal gyrus, a region that has been shown to be involved in perceptual closure (Sehatpour et al., 2006).

\section{Aberrant network activity in ScZ patients during Mooney face perception}

FE-ScZ patients were characterized by a reduced discrimination ability $\left(\mathrm{A}^{\prime}\right)$ and a decrease in detection accuracy for both categories of stimuli. In addition, there was a trend toward an impaired ability to improve RTs during stimulus repetition, suggesting dysfunctional perceptual learning in the FE-ScZ group.

Sensor-level M100 and M170 responses were intact in FE-ScZ, which contrasts with previous studies in chronic ScZ reporting reduced ERP responses during face processing (Lee et al., 2010). The only difference for sensor-level ERF components was observed for the M250, which has been related to closure processes during perception of fragmentary/incomplete visual information (Doniger et al., 2002).

The source analysis of ERF components revealed, however, a more extended pattern of dysfunctions in FE-ScZ. We found increased M100 amplitudes in FEScZ patients in response to face stimuli relative to controls, in sensory (primary motor and primary somatosensory cortex), face (fusiform gyrus, orbitofrontal cortex), and memory (precuneus) regions. Similar to the M100 component, face-related M170 amplitudes were also elevated in FE-ScZ within the left parahippocampal and right inferior occipital gyri and within the postcentral, fusiform, lingual, and superior temporal gyri bilaterally. Contrary to early MEG components, the M250 amplitude in FE-SCZ was reduced over medial frontal gyri, the right inferior frontal gyrus, and earlier peak latencies relative to FE-ScZ.

Overall, the increased amplitudes and delayed latency of the M100 to both face and no-face stimuli highlight that the earliest stage of face identification is impaired in FE-ScZ patients. Early face-processing abnormalities are furthermore supported by the increased M170 amplitude in FE-ScZ. These findings are consistent with a large body of work implicating impaired sensory signaling in ScZ as a mechanism for impaired perceptual and cognitive processes. (Javitt, 2009; Yeap et al., 2009; Rissling et al., 2010). This reduced bottom-up-driven sensory precision could lead to a compensatory excessive reliance on top-down information, as reflected by the M250, thus potentially causing a state of aberrant salience, the tendency to assign meaning to otherwise irrelevant information (Kapur, 2003). This is further supported by our data showing reduced behavioral accuracy and discrimination ability in FE-ScZ with respect to controls.

To examine whether the abnormalities in ERF responses in FE-ScZ are related to impaired perceptual learning, we compared ERF responses to the first versus the second half of trials. Results showed that the increased M100 and M170 responses in FE-ScZ can only be partially explained by a failure to adapt to repeated stimulus presentation. In controls, the M170 face activity was significantly decreased between the first and second half of trials within the left/right middle cingulate cortex, left middle frontal gyrus, left parahippocampal gyrus, and right fusiform gyrus, whereas in the FE-ScZ group, this effect was absent. Specific repetition suppression of the M170 component is consistent with evidence that neural populations in the ventral stream use predictions regarding expected inputs that lead to reduced activation in face-sensitive areas such as the fusiform gyrus (Yovel and Kanwisher, 2004). In FE-ScZ, this mechanism seems to be impaired, because the M170 was not modulated by repeated exposure to face stimuli, which is in agreement with previous EEG and AMRI studies (Onitsuka et al., 2009; Schwartz et al., 2013) and with the behavioral evidence of a failure to adapt RTs during stimulus repetition.

Impaired E/I balance of neural circuits in FE-ScZ: relationship to previous research and pathophysiological hypotheses

Elevated M100 and M170 responses in FE-ScZ are potentially compatible with the possible role of aberrant glutamatergic neu- 
rotransmission at illness onset. Schobel et al. (2013) demonstrated glutamatergic-mediated hypermetabolism as an early marker for the beginning of psychosis. Ketamine, an antagonist of the NMDAR, reproduces this pattern and furthermore leads to a disturbance in E/I-balance parameters, as demonstrated through elevated firing rates, BOLD activity, and neural oscillations (Abel et al., 2003; De Simoni et al., 2013). Moreover, there is preliminary evidence that ketamine leads to an increase of ERP amplitudes and latencies (Church and Gritzke, 1987; Connolly et al., 2004; Schmidt et al., 2013a) and impairs perceptual learning, both of which are compatible with the present findings. Finally, it is also conceivable that deficits in NMDARs effect circuit functions by affecting GABAergic interneurons (Behrens et al., 2007), thus inducing a transitory state of disinhibition (Schobel et al., 2013). Because E/I balance parameters are crucial for the emergence of coordinated network oscillations, in particular at beta/ gamma-band frequencies (Uhlhaas and Singer, 2012), the present findings are potentially compatible with the observation of reduced gamma-band activity and a failure to downregulate beta-band activity during Mooney face processing (Sun et al., 2013).

Our results are also consistent with previous fMRI work demonstrating increased activity during face perception in people at risk of psychosis (Seiferth et al., 2008), thus highlighting the importance of early perceptual deficits in the explanation of facerelated processing impairments in ScZ. Although previous work has highlighted impairments in dorsal stream functioning underlying early visual processing deficits (Doniger et al., 2002; Butler et al., 2007), the high-contrast levels of Mooney faces are mainly targeting parvocellular pathways that project predominantly to the ventral stream. Therefore, it is likely that, in addition to dorsal stream impairments, ventral stream dysfunctions are also involved in perceptual deficits in FE-ScZ (Plomp et al., 2013).

\section{Summary}

Our study shows that source reconstructed ERF responses in MEG data may allow novel insights into the neurophysiological basis of complex visual processing deficits in ScZ. The results demonstrate that individuals with FE-ScZ are characterized by a dysregulation of neuronal activity, as indicated by increase ERF responses during early face processing (i.e., M100 and M170) and by an hypoactivity of regions involved in late face processing (i.e., M250). We suggest that the early hyperactivity could be due to a shift of the excitation/inhibition balance toward excitation, which can be potentially driven by NMDAR hypofunction and is furthermore consistent with impaired perceptual learning in FE-ScZ.

The difference between sensor- and source-level results may reflect the fact that sensor-level data can be complicated due to the cancellation of sources (Hari and Salmelin, 2012). MRIconstrained source reconstruction of MEG data may thus allow a clearer insight into the electrophysiological dysfunctions (Gross et al., 2013). Future studies could investigate the potential contribution of low-frequency (theta/ $\alpha$ ) activity and compare source-level ERF responses between chronic and FE-ScZ patients and the effects of NMDAR antagonists such as ketamine on neuromagnetic activity.

\section{References}

Abel KM, Allin MP, Kucharska-Pietura K, Andrew C, Williams S, David AS, Phillips ML (2003) Ketamine and fMRI BOLD signal: distinguishing between effects mediated by change in blood flow versus change in cognitive state. Hum Brain Mapp 18:135-145. CrossRef Medline
Anderson MJ, Ter Braak CJF (2003) Permutation tests for multi-factorial analysis of variance. Journal of Statistical Computation Simulation 78:85-113.

Bachmann S, Weisbrod M, Röhrig M, Schröder J, Thomas C, Scherg M, Rupp A (2010) MEG does not reveal impaired sensory gating in first-episode schizophrenia. Schizophr Res 121:131-138. CrossRef Medline

Bar M, Kassam KS, Ghuman AS, Boshyan J, Schmidt AM, Dale AM, Hämäläinen MS, Marinkovic K, Schacter DL, Rosen BR, Halgren E (2006) Top-down facilitation of visual recognition. Proc Natl Acad Sci U S A 103:449-454. CrossRef Medline

Barbeau EJ, Taylor MJ, Regis J, Marquis P, Chauvel P, Liégeois-Chauvel C (2008) Spatio temporal dynamics of face recognition. Cereb Cortex 18: 997-1009. CrossRef Medline

Behrens MM, Ali SS, Dao DN, Lucero J, Shekhtman G, Quick KL, Dugan LL (2007) Ketamine-induced loss of phenotype of fast-spiking interneurons is mediated by NADPH-oxidase. Science 318:1645-1647. CrossRef Medline

Bickel S, Javitt DC (2009) Neurophysiological and neurochemical animal models of schizophrenia: focus on glutamate. Behav Brain Res 204:352362. CrossRef Medline

Butler PD, Martinez A, Foxe JJ, Kim D, Zemon V, Silipo G, Mahoney J, Shpaner M, Jalbrzikowski M, Javitt DC (2007) Subcortical visual dysfunction in schizophrenia drives secondary cortical impairments. Brain 130:417-430. CrossRef Medline

Caharel S, Jacques C, d'Arripe O, Ramon M, Rossion B (2011) Early electrophysiological correlates of adaptation to personally familiar and unfamiliar faces across viewpoint changes. Brain Res 1387:85-98. CrossRef Medline

Castelhano J, Rebola J, Leitão B, Rodriguez E, Castelo-Branco M (2013) To perceive or not perceive: the role of gamma-band activity in signaling object percepts. PLoS One 8:e66363. CrossRef Medline

Church MW, Gritzke R (1987) Effects of ketamine anesthesia on the rat brain-stem auditory evoked potential as a function of dose and stimulus intensity. Electroencephalogr Clin Neurophysiol 67:570-583. CrossRef Medline

Connolly PM, Maxwell C, Liang Y, Kahn JB, Kanes SJ, Abel T, Gur RE, Turetsky BI, Siegel SJ (2004) The effects of ketamine vary among inbred mouse strains and mimic schizophrenia for the P80, but not P20 or N40 auditory ERP components. Neurochem Res 29:1179-1188. CrossRef Medline

De Simoni S, Schwarz AJ, O'Daly OG, Marquand AF, Brittain C, Gonzales C, Stephenson S, Williams SC, Mehta MA (2013) Test-retest reliability of the BOLD pharmacological MRI response to ketamine in healthy volunteers. Neuroimage 64:75-90. CrossRef Medline

Dias EC, Butler PD, Hoptman MJ, Javitt DC (2011) Early sensory contributions to contextual encoding deficits in schizophrenia. Arch Gen Psychiatry 68:654-664. CrossRef Medline

Doniger GM, Foxe JJ, Murray MM, Higgins BA, Javitt DC (2002) Impaired visual object recognition and dorsal/ventral stream interaction in schizophrenia. Arch Gen Psychiatry 59:1011-1020. CrossRef Medline

Eimer M, Gosling A, Nicholas S, Kiss M (2011) The N170 component and its links to configural face processing: a rapid neural adaptation study. Brain Res 1376:76-87. CrossRef Medline

Ford JM (1999) Schizophrenia: the broken P300 and beyond. Psychophysiology 36:667-682. CrossRef Medline

Freedman R, Adler LE, Waldo MC, Pachtman E, Franks RD (1983) Neurophysiological evidence for a deficit in inhibitory pathways in schizophrenia: comparison of medicated and drug-free patients. Biol Psychiatry 18: 537-551. Medline

George N, Jemel B, Fiori N, Chaby L, Renault B (2005) Electrophysiological correlates of facial decision: insights from upright and upside-down Mooney-face perception. Brain Res Cogn Brain Res 24:663-673. CrossRef Medline

Gorno-Tempini ML, Price CJ, Josephs O, Vandenberghe R, Cappa SF, Kapur N, Frackowiak RS (1998) The neural systems sustaining faces and proper-name processing. Brain 121:2103-2118. CrossRef Medline

Grier JB (1971) Nonparametric indexes for sensitivity and bias: Computing formulas. Psychol Bull 75:424-429. CrossRef Medline

Gross J, Baillet S, Barnes GR, Henson RN, Hillebrand A, Jenson O, Jerbik K, Litvak V, Maess B, Oostenveld R, Parkkonen L, Taylor JR, van Wassenhove V, Wibral M, Schoffelen JM (2013) Good practice for conducting 
and returning MEG research. Neuroimage 65:349-363. CrossRef Medline

Grützner C, Uhlhaas PJ, Genc E, Kohler A, Singer W, Wibral M (2010) Neuroelectromagnetic correlates of perceptual closure processes. J Neurosci 30:8342-8352. CrossRef Medline

Hari R, Salmelin R (2012) Magnetoencephalography: From SQUIDS to neuroscience. Neuroimage 20th anniversary special edition. 61:386-396. CrossRef Medline

Harris AM, Aguirre GK (2008) The effects of parts, wholes, and familiarity on face-selective responses in MEG. J Vis 8:4.1-4.12. CrossRef Medline

Harris A, Nakayama K (2008) Rapid adaptation of the M170 response: importance of face parts. Cereb Cortex 18:467-476. CrossRef Medline

Herrmann MJ, Ellgring H, Fallgatter AJ (2004) Early-stage face processing dysfunction in patients with schizophrenia. Am J Psychiatry 161:915-917. CrossRef Medline

Javitt DC (2009) Sensory processing in schizophrenia: neither simple nor intact. Schizophr Bull 35:1059-1064. CrossRef Medline

Kapur S (2003) Psychosis as a state of aberrant salience: a framework linking biology, phenomenology, and pharmacology in schizophrenia. Am J Psychiatry 160:13-23. CrossRef Medline

Kay SR, Opler LA, Fiszbein A (1986) Significance of positive and negative syndromes in chronic schizophrenia. Br J Psychiatry 149:439-448. CrossRef Medline

Kegeles LS, Mao X, Stanford AD, Girgis R, Ojeil N, Xu X, Gil R, Slifstein M, Abi-Dargham A, Lisanby SH, Shungu DC (2012) Elevated prefrontal cortex gamma-aminobutyric acid and glutamate-glutamine levels in schizophrenia measured in vivo with proton magnetic resonance spectroscopy. Arch Gen Psychiatry 69:449-459. CrossRef Medline

Kleinschmidt A, Bear MF, Singer W (1987) Blockade of "NMDA" receptors disrupts experience-dependent plasticity of kitten striate cortex. Science 238:355-358. CrossRef Medline

Lafontaine MP, Théoret H, Gosselin F, Lippé S (2013) Transcranial direct current stimulation of the dorsolateral prefrontal cortex modulates repetition suppression to unfamiliar faces: an ERP study. PLoS One 8:e81721. CrossRef Medline

Lee SH, Kim EY, Kim S, Bae SM (2010) Event-related potential patterns and gender effects underlying facial affect processing in schizophrenia patients. Neurosci Res 67:172-180. CrossRef Medline

Lehrl S (2005) Mehrfachwahl-Wortschatz-Intelligenztest MWT-B. Balingen: Spitta Verlag.

Leveroni CL, Seidenberg M, Mayer AR, Mead LA, Binder JR, Rao SM (2000) Neural systems underlying the recognition of familiar and newly learned faces. J Neurosci 20:878-886. Medline

Lindenmayer JP, Bernstein-Hyman R, Grochowski S, Bark N (1995) Psychopathology of schizophrenia: initial validation of a 5 -factor model. Psychopathology 28:22-31. CrossRef Medline

Litvak V, Mattout J, Kiebel S, Phillips C, Henson RN, Kilner J, G. B., Oostenveld R, Daunizeau J, Flandin G, Penny WD, Friston KJ (2011) EEG and MEG data analysis in SPM8. Comput Intell Neurosci 2011:852961. CrossRef Medline

Liu J, Harris A, Kanwisher N (2002) Stages of processing in face perception: an MEG study. Nat Neurosci 5:910-916. CrossRef Medline

Liu J, Harris A, Kanwisher N (2010) Perception of face parts and face configurations: An fMRI study. J Cogn Neurosci 22:203-211. CrossRef Medline

Luck SJ, Mathalon DH, O’Donnell BF, Hämäläinen MS, Spencer KM, Javitt DC, Uhlhaas PJ (2011) A roadmap for the development and validation of event-related potentials biomarkers in schizophrenia research. Biol Psychiatry 70:28-34. CrossRef Medline

Mooney CM, Ferguson GA (1951) A new closure test. Can J Psychol 5:129133. CrossRef Medline

Onitsuka T, Niznikiewicz MA, Spencer KM, Frumin M, Kuroki N, Lucia LC, Shenton ME, McCarley RW (2006) Functional and structural deficits in brain regions subserving face perception in schizophrenia. Am J Psychiatry 163:455-462. CrossRef Medline

Onitsuka T, Spencer KM, Lucia LC, Shenton ME, McCarley RW, Niznikiewicz MA (2009) Abnormal asimmetry of the face N170 repetition effect in male patients with chronic schizophrenia. Brain Imaging Behav 3:240 245. CrossRef Medline

Philpot BD, Cho KK, Bear MF (2007) Obligatory role of NR2A for metaplasticity in visual cortex. Neuron 53:495-502. CrossRef Medline
Plomp G, Roinishvili M, Chkonia E, Kapanadze G, Kereselidze M, Brand A, Herzog MH (2013) Electrophysiological evidence for ventral stream deficits in schizophrenia patients. Schizophr Bull 39:547-554. CrossRef Medline

Rissling AJ, Makeig S, Braff DL, Light GA (2010) Neurophysiologic markers of abnormal brain activity in schizophrenia. Curr Psychiatry Rep 12:572578. CrossRef Medline

Rivolta D, Palermo R, Schmalzl L, Williams MA (2012b) Investigating the features of the M170 in congenital prosopagnosia. Front Hum Neurosci 6:45. CrossRef Medline

Rivolta D, Palermo R, Schmalzl L, Williams MA (2012c) An early categoryspecific neural response for the perception of both places and faces. Cogn Neurosci 3:45-51. CrossRef Medline

Salisbury DF, Shenton ME, Carlye B, Griggs CB, Bonner-Jackson A, McCarley RW (2002) Mismatch negativity in chronic schizophrenia and firstepisode schizophrenia. Arch Gen Psychiatry 59:686-694. CrossRef Medline

Schmidt A, Kometer M, Bachmann R, Seifritz E, Vollenweider F (2013a) The NMDA antagonist ketamine and the 5-HT agonist psilocybin produce dissociable effects on structural encoding of emotional face expressions. Psychopharmacology (Berl) 225:227-239. CrossRef Medline

Schmidt A, Diaconescu AO, Kometer M, Friston KJ, Stephan KE, Vollenweider FX (2013b) Modeling ketamine effects on synaptic plasticity during the mismatch negativity. Cereb Cortex 23:2394-2406. CrossRef Medline

Schobel SA, Chaudhury NH, Khan UA, Paniagua B, Styner MA, Asllani I, Inbar BP, Corcoran CM, Lieberman JA, Moore H, Small SA (2013) Imaging patients with psychosis and a mouse model establishes a spreading pattern of hippocampal dysfunction and implicates glutamate as a driver. Neuron 78:81-93. CrossRef Medline

Schwartz BL, Vaidya CJ, Shook D, Deutsch SI (2013) Neural basis of implicit memory for socio-emotional information in schizophrenia. Psychiatry Res 206:173-180. CrossRef Medline

Schweinberger SR, Pickering EC, Jentzsch I, Burton AM, Kaufmann JM (2002) Event-related brain potential evidence for a response of inferior temporal cortex to familiar face repetitions. Brain Res Cogn Brain Res 14:398-409. CrossRef Medline

Sehatpour P, Molholm S, Javitt DC, Foxe JJ (2006) Spatiotemporal dynamics of human object recognition processing: an integrated high-density electrical mapping and functional imaging study of "closure" processes. Neuroimage 29:605-618. CrossRef Medline

Seiferth NY, Pauly K, Habel U, Kellermann T, Shah NJ, Ruhrmann S, Klosterkötter J, Schneider F, Kircher T (2008) Increased neural response related to neutral faces in individuals at risk for psychosis. Neuroimage 40:289-297. CrossRef Medline

Suckling J, Bullmore E (2004) Permutation tests for factorially designed neuroimaging experiments. Hum Brain Mapp 22:193-205. CrossRef Medline

Sun L, Castellanos N, Grützner C, Koethe D, Rivolta D, Wibral M, Kranaster L, Singer W, Leweke MF, Uhlhaas PJ (2013) Evidence for dysregulated high-frequency oscillations during sensory processing in medicationnaive, first episode schizophrenia. Schizophr Res 150:519-525. CrossRef Medline

Tost H, Braus DF, Hakimi S, Ruf M, Vollmert C, Hohn F, Meyer-Lindenberg A (2010) Acute D2 receptor blockade induces rapid, reversible remodeling in human cortical-striatal circuits. Nat Neurosci 13:920-922. CrossRef Medline

Uhlhaas PJ, Singer W (2012) Neuronal dynamics and neuropsychiatric disorders: Towards a translational paradigm for dysfunctional large-scale networks. Neuron 75:963-980. CrossRef Medline

Umbricht DS, Bates JA, Lieberman JA, Kane JM, Javitt DC (2006) Electrophysiological indices of automatic and controlled auditory information processing in first-episode, recent-onset and chronic schizophrenia. Biol Psychiatry 59:762-772. Medline

Yeap S, Kelly SP, Reilly RB, Thakore JH, Foxe JJ (2009) Visual sensory processing deficits in patients with bipolar disorder revealed through highdensity electrical mapping. J Psychiatry Neurosci 34:459-464. Medline

Yovel G, Kanwisher N (2004) Face perception: domain specific, not process specific. Neuron 44:747-748. CrossRef Medline 